\title{
Práticas Tarifárias do Setor de Saneamento Brasileiro
}

\author{
Valmir de Albuquerque Pedrosa \\ Universidade Federal de Alagoas e o Instituto de Pesquisas Hidráulicas/UFRGS - Caixa Postal 15029 \\ 91501-97o Porto Alegre, RS - pedrosa@if.ufrgs.br \\ Recebido: 24/02/oo - revisão: 12/12/oo - aceito: 05/03/01
}

\begin{abstract}
RESUMO
Este texto apresenta uma discussão sobre as práticas tarifárias do setor de saneamento, dentro de um contexto histórico das políticas nacionais para o setor. É explorado principalmente o período de atuação do PLANASA (Plano Nacional de Saneamento) e das políticas do extinto BNH (Banco Nacional de Habitação). Assim, o quadro de dificuldades da economia nacional é analisado para se estabelecer sua correlação com a situação financeira atual das empresas de saneamento. As práticas tarifárias do setor são apresentadas, bem como os objetivos perseguidos com estas. Como exemplo, as práticas brasileiras e chilenas são expostas, observando-se as disparidades nas políticas de subsídios existentes entre ambas: no Brasil, com um subsídio indireto nas contas de água e esgoto; no Chile, por meio de formas diretas. Finalmente, dessa análise feita, são extraídas algumas indicações para um primeiro diagnóstico dos entraves da estrutura financeira do setor de saneamento brasileiro.
\end{abstract}

Palavras-chave: tarifas; saneamento.

\section{BREVE HISTÓRICO DAS POLÍTICAS DE SANEAMENTO NO BRASIL}

O serviço de saneamento básico brasileiro, entendido neste texto como o serviço de água e esgoto para aglomerados urbanos, atravessou profundas mudanças neste século. Numa revisão do contexto histórico, é possível separar cinco grandes períodos:

1. Até 1968, onde o setor era caracterizado por flexibilidade, estatização e descentralização;

2. Entre 1968 e 1970, onde se caracteriza a criação do Sistema Financeiro de Saneamento e dos instrumentos básicos de financiamento;

3. Entre 1971 e 1984, época em que a vigorosa expansão econômica que caracterizou o "milagre brasileiro" criou condições para a atuação do Plano Nacional de Saneamento (PLANASA), o que alterou os índices de cobertura e nível deste serviço;

4. Entre 1985 e 1989, fase da redemocratização nacional, inclusive com a promulgação da nova Constituição, em que se alterou a estrutura do PLANASA, na era da denominada Nova República;

5. E, finalmente, de 1990 até os dias atuais, com a extinção do PLANASA e a busca de um novo modelo para o setor e a presença do Plano Nacional de Desestatização (PND), sinalizando com profundas mudanças nos horizontes de médio e longo prazo.

A retrospectiva a seguir, tem como elemento catalisador as práticas tarifárias adotadas na história deste setor.

No início dos anos 30, o desenvolvimento urbano e industrial exigiu do setor público, importantes investimentos para fazer face à crescente necessidade dos serviços de saneamento, bem como outros serviços de infra-estrutura, como estradas e energia. Porém, a crise mundial ainda estava recente. A ferida aberta com a bolsa em Nova Iorque pela quinta-feira negra, de 24 de outubro de 1929, e pela terça seguinte, anunciava a chegada de um período conhecido como a grande depressão, onde os investimentos caíram assustadoramente em todo mundo (Galbraith, 1991).

Até esta data havia a participação de empresas públicas e privadas no setor de saneamento no Brasil, neste último grupo com forte presença de concessionárias estrangeiras. Os serviços eram de amplitude limitada, pelo tamanho reduzido das populações urbanas. Como não havia subsídio, as 
tarifas cobriam inteiramente os custos, inclusive com uma garantia de rentabilidade mínima. Essa rentabilidade situava-se por volta de $7 \%$ (Brasil, 1995b). O poder público detinha poder normativo e fiscalizador, com definição descentralizada de tarifas.

Em 1934 foi promulgado o Código de Águas, que dava poder ao governo federal de fixar tarifas para a água. Nascia a intervenção governamental no setor. As empresas estrangeiras foram nacionalizadas e estatizadas. Destinadas a favorecer o crescimento econômico, as tarifas eram fixadas abaixo dos valores reais.

Com o acelerado crescimento populacional nas décadas seguintes, agravam-se as crônicas deficiências do serviço de saneamento. Para se ter uma idéia da cobertura do serviço, em 1960, apenas $43 \%$ dos domicílios nacionais eram ligados à rede de água e apenas $27 \%$ à de esgoto. Apesar das décadas favoráveis à economia nacional, os investimentos em saneamento minguavam.

Vem o movimento militar de 1964 e iniciase o governo Castelo Branco. Em 1966, é criado o Banco Nacional de Habitação (BNH), tendo como seu braço financeiro o Sistema Financeiro de Habitação (SFH) e como papel, implantar uma política de desenvolvimento urbano. Em 1968, cria-se o Sistema Financeiro de Saneamento (SFS). Esse período é marcado por forte centralização política, além de amplas reformas tributárias.

No bojo dessas reformas, em 1966, é criado o Fundo de Garantia por Tempo de Serviço (FGTS) que viria a ser o principal suporte financeiro de toda política de saneamento. Esse instrumento tinha dupla função de fundo indenizatório (em caso de demissão do empregado) e fonte de financiamento da política habitacional de interesse social. Contudo, somente em 1969 o Decreto-Lei No 949 autoriza o BNH a aplicar tais recursos no setor saneamento. Dessa forma, estavam criadas as condições para a expansão do setor. Paralelamente, seguia com força a centralização do poder político e financeiro em favor da União, em detrimento dos Estados e municípios.

Em 1967 é apresentado o Plano Decenal de Desenvolvimento Econômico e Social (1967 a 1976) que, apesar de nunca ter sido colocado em prática, serviu de base para a definição de algumas políticas públicas. Neste, vaticinava-se que as tarifas dos serviços de saneamento básico deveriam ser pagas em termos econômicos reais, para que propiciassem, inclusive, a reposição do capital, além da criação de uma sobretarifa, destinada a fortalecer um fundo de investimentos.

Nesse contexto, no período de 1968 a 1970, o BNH e o SFS estimularam a criação das Companhias Estaduais de Saneamento Básico (CESBs) como principais agentes de implantação da política de saneamento. Concomitantemente, pregava a criação dos Fundos Estaduais de Água e Esgoto (FAEs) para fornecer a indispensável contrapartida estadual aos empréstimos do SFS. Solidificava-se o $\mathrm{BNH}$ como órgão central e normativo do Sistema Financeiro de Saneamento (SFS) e as CESBs como órgãos executores do programa, em nível estadual.

O BNH e o SFS justificavam, por um lado, que, com a existência de uma única empresa de saneamento por Estado, obter-se-iam economias de escala, que permitiriam reduzir os custos e assegurar, ainda, a efetivação do subsídio cruzado, pelo qual os municípios com maiores recursos subsidiariam os municípios mais pobres. Por outro lado, em cada Estado os FAEs foram criados por meio de convênio entre o Ministério do Interior, o BNH e os governos estaduais. Encontravam-se sob responsabilidade da pasta do então Ministério do Interior as políticas de saneamento.

Em 1971, é criado o Plano Nacional de Saneamento (PLANASA), que se constituiria na experiência nacional mais importante no campo do saneamento básico. Tinha como preocupação central a universalização dos serviços de saneamento entre outros objetivos. No tocante às políticas tarifárias pregava:

a. Auto-sustentação das CESBs por meio do aumento do recurso a nível estadual, por parte dos FAEs;

b. Adequação dos níveis tarifários à capacidade de pagamento da população, sem prejuízo do equilíbrio entre receita e custo dos serviços;

c. A remuneração anual de $12 \%$ sobre o investimento reconhecido, em benefício do responsável pela execução do serviço.

A centralização do poder continuava. A Lei No 6.528, de maio de 1978, atribui ao Ministério do Interior a responsabilidade pela fixação das condições de operação de serviços públicos de saneamento básico, dentro do Plano Nacional de Saneamento. A esse ministério caberia estabelecer normas gerais de tarifação, coordenar, orientar e fiscalizar a execução de serviços de saneamento e 
assegurar a assistência financeira, quando necessária. A lei estabelecia que a fixação tarifária levaria em conta a viabilidade do equilíbrio econômicofinanceiro das companhias estaduais de saneamento básico e a preservação dos aspectos sociais, de forma a assegurar o adequado atendimento de usuários de menor consumo, com base em tarifa mínima.

Para entender melhor as razões da inadimplência, é apresentado abaixo um quadro síntese com as principais condições de financiamento do PLANASA.

Até então, cada CESB possuía critérios próprios para definição de sua tarifa, a partir das orientações estabelecidas pelo BNH. Em alguns casos, o reajuste era submetido ao Conselho Interministerial de Preços e em outros, aos governos estaduais.

Porém, com o Decreto 82.587, de 1978, que regulamentou a lei em tela, estabeleceu-se a seguinte sistemática para a fixação de tarifas:

a. O Ministério do Interior estabelecia normas gerais de tarifação e fiscalizava a sua aplicação;

b. Aos governos estaduais, por meio das CESBs, cabia a realização de estudos e propostas tarifárias;

c. O BNH responsabilizava-se pela análise das propostas que, em seguida, eram submetidas ao MINTER, que autorizava o reajuste após aprovação do CIP (Conselho Interministerial de Preços).

A manutenção das tarifas em níveis reais era considerada pelo PLANASA condição básica para a auto-sustentação das CESBs. Porém, sua utilização como um dos instrumentos de controle da inflação, reajustando-as abaixo dos índices, foi um dos motivos dos problemas enfrentados pelo setor. A partir de 1978, a tarifa média cobrada dos usuários foi insuficiente para cobrir o custo médio dos serviços.

O Decreto No 82.587 também estabelecia em seu artigo 10 que as tarifas seriam diferenciadas segundo categorias de usuários e faixas de consumo, assegurando o subsídio dos usuários de maior poder aquisitivo para aqueles de menor renda, assim como dos grandes para os pequenos consumidores.

As categorias de consumo compreendiam: residencial, comercial, industrial e público. O artigo 14 estabelecia que as tarifas da categoria residencial
Tabela 1. Condições usuais de financiamento do PLANASA.

\begin{tabular}{lc}
\hline Condições & PLANASA (em 1986) \\
\hline Prazo de amortização & 18 ou 30 anos \\
Carência & 3 ou 4,5 anos \\
Período de amortização & Mensal \\
Contrapartida financeira & $50 \%$ \\
Fonte da contrapartida & Estado (FAE) \\
Plano de reajustamento & Variação da OTN \\
Taxa anual de juros & 2,5 a 10,5\% \\
Taxa de administração & $2 \%$ \\
\hline
\end{tabular}

Obs.: As condições variaram ao longo dos anos, bem como entre estados da União.

seriam diferenciadas para as diversas faixas de consumo, devendo, em função destas, ser progressivas em relação ao volume faturável.

Já os usuários das categorias comercial e industrial deveriam ter duas tarifas específicas, uma referente ao volume mínimo e outra ao excedente, sendo que a segunda seria superior à primeira e esta maior que a tarifa média.

Como se tratava de monopólio natural, as tarifas seriam reguladas através do método de tarifação pelo custo do serviço, garantindo-se às companhias estaduais, em condições eficientes de operação, a remuneração de até $12 \%$ sobre o investimento reconhecido. Esse método também conhecido como regulação da taxa interna de retorno, será discutido adiante.

Em 1991, é revogado o Decreto 82.587, devolvendo-se às concessionárias a autonomia para fixar tarifas de acordo com suas necessidades.

\section{AS PRÁTICAS TARIFÁRIAS NO PERÍODO DO PLANASA}

A implantação do PLANASA foi iniciada num período de expansão acelerada da economia brasileira. Mesmo assim, isso não significou que sua implantação estivesse livre de problemas. No período de sua criação, ao fim do ciclo dos governos militares, o PLANASA encontrou dificuldades e sofreu mudanças ao longo do tempo sem, entretanto, modificar seus objetivos básicos.

Entre os problemas enfrentados estava a manutenção das preconizadas tarifas reais. De imediato, observou-se que grande parte da população de baixa renda não disporia de recursos para 
pagar o preço necessário, mesmo utilizando o subsídio cruzado. A possibilidade dos consumidores mais ricos subsidiarem os mais pobres tinha, obviamente, limites.

Outro problema foi o número elevado de municípios que decidiram não participar do PLANASA, nem efetivaram a concessão dos serviços às CESBs. De modo geral, eram municípios de porte do Sul-Sudeste, como Porto Alegre, Volta Redonda, Ribeirão Preto, Campinas, Caxias do Sul, Juiz de Fora, Osasco, entre muitos outros.

Em 1984, é criada Associação dos Serviços Municipais de Água e Esgostos (ASSEMAE) integrada por mais de mil municípios que não se filiaram ao PLANASA e que, por essa razão, não recebiam financiamento do $\mathrm{BNH} / \mathrm{SFS}$.

Além do mais, o fôlego da inflação no final da década de 70, e sua elevação nos anos 80, induziu a adoção de medidas para baixá-la, como a contenção das tarifas e dos preços dos serviços e bens produzidos pelo setor público.

Passados o período de carência dos empréstimos e os primeiros anos de retorno das aplicações, as CESBs e os governos estaduais tiveram dificuldades em saldar seus compromissos, tornando-se cada vez mais inadimplentes. Assim foi que o volume de investimentos do PLANASA reduziu-se significativamente no período de 1983 a 1986.

Neste horizonte de incertezas para o setor de saneamento, surge a Carta Magna de 1988, com um capítulo dedicado exclusivamente à política urbana. Diversos de seus dispositivos estão relacionados ao setor de saneamento.

Paralelamente o PLANASA sofreu diversas e importantes modificações graças, em parte, ao ambiente político criado pela redemocratização, que abriu espaços para a reinvidicação política.

Do ponto de vista institucional, uma nova pasta foi criada no governo federal, em 1985, para tratar da questões urbanas: o Ministério do Desenvolvimento Urbano e Meio Ambiente (MDU), que trouxe para sua esfera o BNH, o PLANASA, os programas habitacionais do $\mathrm{SFH}$ e os assuntos do meio ambiente, funções desmembradas do antigo Ministério do Interior (MINTER).

A reivindicação da ASSEMAE de que os órgãos municipais autônomos participassem do PLANASA foi atendida. As mesmas condições estabelecidas para as CESBs passaram a vigorar para os municípios, isto é, o $\mathrm{BNH}$ emprestava 50\% dos investimentos e as prefeituras arcavam com igual percentual, sendo facultada a criação de fundos municipais de financiamento, nos moldes dos FAEs. A concessão de financiamento, em vez de basear-se nos estudos de viabilidade global de toda a empresa, caso das CESBs, passou a ser feita de projeto a projeto, para as prefeituras.
A incorporação do BNH pela Caixa Econômica Federal (em novembro de 1986) inaugurou uma prolongada crise institucional do setor, que perdura até os dias atuais.

Ao analisar os problemas do PLANASA em geral e das CESBs em particular, o IPEA (Instituto de Pesquisa Econômica Aplicada), em 1987, manifestou-se do seguinte modo:

“A má situação das empresas estaduais de saneamento é conseqüência dos altos investimentos realizados, seja pela utilização de tecnologias sofisticadas, seja por toda sorte de desperdício. A receita operacional dessas empresas apenas eqüivale às despesas de exploração, sendo o serviço da dívida coberto, em grande parte, por novos empréstimos, situação em que se perpetua uma defasagem entre a receita e as despesas totais. Anteriormente, para cobrir o déficit, vinha sendo prática corrente a realização de subsídio, por parte dos Estados, às companhias de saneamento básico, o que não está sendo possível.

A recuperação financeira dessas companhias deverá, necessariamente, passar por reformulação tarifária que hoje se apresenta de forma injusta, pois privilegia o confronto de uns poucos às custas dos riscos à saúde de parcelas expressivas da população”.

A Associação de Empresas de Saneamento Básico Estaduais (AESBE) apontou como principais dificuldades financeiras, a política tarifária inadequada, a expansão dos serviços às periferias urbanas e localidades pequenas, que não permitem o retorno adequado dos investimentos via tarifas, e as conseqüências negativas do Plano Cruzado, em especial o congelamento de tarifas.

No governo Collor, iniciado em 1991, extingüiu-se o Ministério do Interior, dissolvendo-se com ele todos os órgãos ligados às questões urbanas e ao saneamento. $\mathrm{O}$ trato dos problemas urbanos ficou reduzido ao binômio habitação e saneamento, entregues, respectivamente, às novas Secretarias Nacionais de Habitação e de Saneamento, abrigadas no também recém-criado Ministério da Ação Social (MAS).

Enquanto isso, o Conselho Curador do FGTS, ficou localizado no Ministério do Trabalho e da Previdência Social, a Caixa Econômica Federal permaneceu na área fazendária, subordinada ao Ministério da Economia, Fazenda e Planejamento. 
Estava fragmentado o sistema decisório das ações nacionais em saneamento, com efeitos deletérios sobre o setor.

A Resolução do MAS No 076 de 1992 aprovou a regulamentação referente à unificação das antigas linhas de crédito da área de saneamento em único programa denominado Programa de Saneamento para Núcleos Urbanos (PRONURB), com a conseqüente extinção do PLANASA. Esse programa tem como objetivos atender com saneamento básico a população urbana em geral, especialmente seus segmentos de baixa renda. Entre os seus critérios de prioridade estavam:

a. projetos que se destinem a conferir plena utilização a empreendimentos já beneficiados pelo FGTS;

b. projetos de maior participação percentual da contrapartida na composição do investimento;

c. projetos que busquem racionalizar o processo produtivo mediante ganhos de eficiência, sobretudo visando reduzir o preço das tarifas para o usuário final; entre outros.

O PRONURB tinha uma formação tal que o órgão gestor era o Ministério da Ação Social, por intermédio da Secretaria Nacional de Saneamento, como agente operador a Caixa Econômica Federal, como agentes financeiros a Caixa Econômica Federal e outros agentes autorizados pela legislação em vigor, como agentes promotores os governos estaduais, prefeituras municipais, serviços autônomos municipais e companhias estaduais e municipais de saneamento.

$\mathrm{Na}$ realidade, os pedidos de financiamento, tanto de saneamento como de habitação, eram analisados pela CEF, que dependia de autoridade do MAS para contratação. A disfunção no arranjo institucional ficou patente na queda de braço entre o MAS e a CEF.

Na seqüência, a situação foi alterada, passando as políticas de saneamento para o Ministério do Planejamento e Orçamento, sob responsabilidade da Secretaria de Políticas Urbanas. E atualmente a Secretaria Especial de Desenvolvimento Urbano, ligada diretamente a presidência da república, criada em janeiro de 1999, é a responsável pelas políticas governamentais para o setor.

Para completar esta retrospectiva histórica, caberia relembrar que três anos após a promulgação da Constituição Federal de 1988, iniciou-se na câmara dos deputados a tramitação do Projeto de Lei 53 que, dois anos mais tarde, passou a ser denominado Projeto de Lei da Câmara 199 (PLC 199) dispondo sobre a Política Nacional de Saneamento.
Após quatro anos de tramitação foi votado e aprovado pela câmara federal e senado. Seguindo para sanção presidencial no dia 5 de janeiro de 1995, foi vetado integralmente pelo presidente Fernando Henrique Cardoso, em seu quinto dia de exercício da presidência do Brasil.

\section{Breves ensinamentos das políticas tarifárias desde 1968}

Os problemas da CESBs, derivados do excessivo endividamento e cobrança de tarifas irrealistas, foram agravados pelo fraco desempenho institucional e operacional destas. O padrão de funcionamento foi prejudicado pelos sistemas de baixa produtividade, que registraram perdas de $50 \%$ do volume de água produzido e excessivos custos operacionais e administrativos, esses últimos decorrentes, entre outros fatores, como: ingerências políticas na condução de negócios que deveriam, por princípio, se reger por normas comerciais à margem do sistema político-partidário; ausência de regulação; uma pitada de corporativismo, o que levou a altos salários médios e os riscos associados à condução de um serviço que é um monopólio natural.

Em função da generalizada inadimplência tanto dos Estados quanto das CESBs, do baixo retorno dos empréstimos contratados e da redução da arrecadação líquida do FGTS, o PRONURB, sucessor do PLANASA, encontrou dificuldades em promover investimentos compatíveis com o crescimento populacional e a necessidade de reduzir os déficits existentes.

Não obstante as dificuldades do setor, é preciso destacar o êxito obtido no subsetor de abastecimento de água, que já atende a mais de $85 \%$ da população urbana. E apesar da mais modesta expansão das redes de coleta e tratamento de esgotos houve, também, neste segmento, significativa melhora.

Especificamente sobre as tarifas de água, apesar dos documentos legais estimularem a viabilidade financeira das CESBs via recolhimento tarifário, o controle de definição de tarifas por parte do governo federal, durante o período de 1978 a 1991, 
comprometeu a saúde financeira dessas companhias, ocorrendo, assim, um longo período durante o qual as receitas não cobriam os custos totais. Eram e são comuns os casos onde as tarifas sequer cobrem as despesas com a operação do sistema. Nesse item, merecem destaque as despesas com energia elétrica que respondem por importantes parcelas dos custos de operação das CESBs.

Entre alguns dispositivos legais mais recentes, vale mencionar a Lei № 8.031 de 1990, que instituiu o Programa Nacional de Desestatização (PND), com os objetivos de fortalecer a iniciativa privada em todos os seus campos de atuação, reduzir a interferência do Estado na vida e nas atividades do indivíduo, contribuir para a eficiência e o menor custo dos serviços prestados pela administração pública federal, para que sejam atendidos satisfatoriamente os usuários desse serviço. Dentre esses campos de atuação está o de saneamento. Assim, a regulação do serviço de saneamento, quando este está concedido à empresa privada, passa a ganhar destaque nas políticas de saneamento da agenda do atual governo federal.

Parlatore (1999) faz uma análise da conseqüência do PND no setor de saneamento. Em seu texto, apresenta a relação de serviços de saneamento que foram concedidos à iniciativa privada. Entre eles estão os que atendem as cidades de Limeira (SP), Araruama, Saquarema e Silva Jardim (RJ), Cabo Frio, Búzios e Arraial do Cabo (RJ), Jundiaí (SP), Itú (SP), Petrópolis (RJ), Ribeirão Preto (SP), Jaú (SP), Campos (RJ), Niterói (RJ), Paranaguá (PR), Araçatuba (SP), Mairinque (SP), Ourinhos (SP), Marília (SP) e mais outras 10 cidades.

Adicionalmente, os Estados da Bahia, Minas Gerais, Pará, Santa Catarina, Paraná, Espírito Santo, Mato Grosso, Pernambuco, Rio de Janeiro e São Paulo têm em suas agendas de governo propostas de concessão do setor de fornecimento de água à iniciativa privada. Na seqüência do texto, é abordada a questão da forma e da importância da regulação das políticas tarifárias dentro deste contexto de atuação do setor privado.

\section{POLÍTICAS TARIFÁRIAS NAS EMPRESAS DE SANEAMENTO}

A regulação tarifária é um dos aspectos mais importantes da regulação dos serviços públicos, tendo em vista a necessidade, em um regime de monopólio natural, de se garantir tanto a rentabilidade do investidor quanto a preservação dos interesses dos consumidores.

Em um regime de monopólio natural, a regulação das tarifas reveste-se de especial complexi- dade, tendo em vista, além dos aspectos mencionados anteriormente, o elevado grau de diferença de informações entre quem realiza o serviço e quem o regula. Neste ambiente, a tarifação enfrenta o desafio de resolver as tensões entre as eficiências produtiva, distributiva e alocativa.

O conceito de eficiência produtiva é entendido como a utilização da planta instalada pelo produtor, com máximo rendimento e menor custo, dada a estrutura de mercado. A eficiência distributiva pode ser definida como a capacidade de redução, pela concorrência ou pela regulação, da apropriação indevida de excedentes econômicos por parte do produtor. A eficiência alocativa, por sua vez, é a situação na qual se realiza o maior volume de transações econômicas, gerando a maior renda agregrada possível, que segundo a teoria econômica é garantida sob concorrência perfeita, quando os preços se igualam aos custos marginais.

Para o setor de saneamento concedido à empresa privada, a literatura técnica reconhece três importantes modelos tarifários: a) a tarifação pelo custo do serviço (historicamente adotado no Brasil, conforme já comentado); b) a tarifação com base no custo marginal (modelo adotado pelo Chile desde 1988, que será comentado neste texto em item específico); e c) o price-cap (modelo de origem inglesa, adotado pelo edital de concorrência pública para a concessão de serviço público, para operação, manutenção e ampliação dos sistemas de abastecimento de água e esgotamento sanitário nas bacias hidrográficas da baía de Sepetiba, baixada de Jacarepaguá e das praias oceânicas da zona sul, no município do Rio de Janeiro, com data para outubro de 1999).

Foram desenvolvidos outros instrumentos para complementar os métodos acima descritos, como o intervalo de revisão da tarifa, o mecanismo de yardstick competition (que estabelece padrões de eficiência) e as licitações para concessão de serviço público. A seguir, apresentam-se as principais lições da aplicação desses modelos na esfera internacional.

\section{Tarifação pelo custo do serviço}

A tarifação pelo custo do serviço, conhecido comumente como controle da taxa interna de retorno, é o regime tradicionalmente utilizado para regulação das tarifas dos monopólios naturais. Por exemplo, nos Estados Unidos, apesar de empresas públicas constituírem maioria absoluta no setor de saneamento, quando o serviço é concedido a empresas privadas, a regulação tarifária é feita por meio do controle da taxa interna de retorno. $\mathrm{O}$ mo- 
tivo maior dessa adoção é limitar as receitas da prestadora do serviço, prezando pela modicidade das tarifas.

No caso brasileiro, ainda na época em que as empresas estrangeiras eram responsáveis pela operação do setor de saneamento, o governo garantia uma rentabilidade mínima das concessionárias, caracterizando o controle pela taxa interna de retorno. Nessa época, as tarifas eram reais, pois inexistia necessidade de subsídios, situação que veio a se alterar com o Código de Águas, como já explicado anteriormente.

Cintra apud Brasil (1995), ao estudar o financiamento dos investimentos em infra-estrutura, no período de 1930 até 1970 , encontrou diversos decretos que asseguravam um retorno de $7 \%$ ao ano ao capital investido. Já na década de 60 em diante, previa-se inclusive uma remuneração para a CESBs de até $8 \%$ do capital, operação que de fato nunca ocorreu.

A definição da taxa interna de retorno é uma forma indireta de determinação dos preços, uma vez que por meio de sua aplicação, estes serão reajustados sempre que for necessária a recomposição da receita, de forma a garantir a taxa de retorno permitida pela reguladora.

Uma dificuldade é definir sobre o valor da taxa interna de retorno. O custo de oportunidade do capital pode dar um referência, porém comumente são estudados casos históricos de rentabilidade, bem como as taxas internas de empreendimentos que tenham similitude com o setor, como é o caso do setor elétrico.

Outra dificuldade do método é definir sobre que valor-base deve ser aplicada a taxa de retorno. Assim, estas e outras dúvidas dificultam a simplicidade administrativa do processo, bem como impedem a eficiência econômica, principalmente a alocativa e a distributiva.

Convém reforçar a idéia que a diferença de informação entre o ente regulador e o prestador do serviço é certeza de litígios nas ocasiões da definição de tarifas. Podendo inclusive ocorrer investimentos desnecessários pela prestadora para maximizar lucros, pois caso a rentabilidade assegurada supere a rentabilidade de outros setores, compensaria (sob ótica do empreendedor) investir e retirar lucros elevados dessa situação. Assim, o prestador do serviço pode ter limitado o crescimento das receitas, porém não tem incentivo para ganhar eficiência nos seus processos internos, visto que tem garantida a rentabilidade do investimento.

\section{Tarifação pelo custo marginal}

A grande dificuldade do emprego desse método é o fato dos custos marginais não refletirem os custos fixos, tão elevados neste tipo de atividade econômica. Assim, os custos marginais de curto prazo são consideravelmente menores que os custos médios, significando que as receitas não seriam suficientes para recuperar integralmente as despesas.

Nessa direção, é comum se estabelecer uma receita extra, por meio do pagamento de uma tarifa fixa (independente do consumo de água) por parte do usuário, de forma a gerar a diferença entre as despesas totais e as despesas cobertas pelas receitas de preços via custo marginal. Esse modelo é adotado em várias companhias estaduais de saneamento do Brasil, como exemplo tem-se a Companhia de Saneamento do Paraná, a SANEPAR.

Novamente, as diferenças de informação entre o ente regulador e o prestador do serviço provocam dificuldades na definição das tarifas a serem cobradas. Entretanto, a inclusão dos custos marginais já representa um evolução em relação à regulação da taxa interna de retorno.

\section{Método de price-cap}

O mecanismo de tarifação conhecido como price-cap constitui-se na definição de um preçoteto para os preços médios da firma, corrigidos periodicamente com a evolução de um índice de preços ao consumidor. Além desse, é incluído um fator de produtividade que funciona como uma transferência em favor do consumidor, desonerando as tarifas, no momento em que a eficiência da produção possa reduzir os custos.

O principal argumento favorável a esse método é a eliminação da necessidade de um conhecimento detalhado dos custos da empresa prestadora do serviço. O que nem sempre é possível, eliminando assim os riscos e custos da ação regulatória, presente de forma marcante nos demais métodos.

Nesse método, visualizam-se como duas vantagens, a maior facilidade operacional do ente regulador e o estímulo ao prestador em ganhar eficiência no serviço, haja vista que este último poderá apropriar-se das diferença na redução dos custos que viesse a ocorrer entre os períodos de revisão do price-cap. 
Em relação à qualidade do serviço, verificase nas experiências internacionais que o estímulo à redução dos custos, não assegura necessariamente o aprimoramento do atendimento ao usuário. Ao contrário, a sujeição de um preço-teto médio faz com que a prestadora apresente uma tendência ao subinvestimento para melhoria da qualidade dos serviços, já que esse esforço representaria uma elevação do seu nível de custos.

Num exemplo muito atual de adoção desse método, a Secretaria Municipal de Obras e Serviços Públicos do Município do Rio de Janeiro, por meio da Fundação Rio-Águas, lançou o edital de concorrência pública para a concessão de serviço público para operação, manutenção e ampliação dos sistemas de abastecimento de água e esgotamento sanitário nas bacias hidrográficas da baía de Sepetiba, baixada de Jacarepaguá e das praias oceânicas da zona sul.

Nesse edital, no item 12.2.1, ficou estipulado que as Tarifas Referenciais de Água (TRA) e de Esgoto (TRE) devem ser calculadas considerandose o quadro de receitas e despesas a ser determinado pelo licitante, sendo seu valor limitado superiormente a $\mathrm{R} \$ 0,36 / \mathrm{m}^{3}$ (trinta e seis centavos de real por metro cúbico).

É interessante ressaltar que o índice de perdas físicas de água do sistema de distribuição a ser computado para a tarifação será de $20 \%$, cabendo à concessionária adequar esse parâmetro a seu planejamento. No documento não estão explícitos os intervalos regulatórios para redefinição de tarifas, tampouco como a eficiência nos serviços poderá ser revertida para o usuário por meio de menores tarifas.

Um elemento interessante do processo postulante é que a produção da água continuará a ser realizada pela CEDAE (Companhia Estadual de Água e Esgoto do Rio de Janeiro), que hoje opera o sistema a ser licitado. O vencedor da licitação comprará a água tratada da CEDAE do sistema Guandu, ao preço médio de $\mathrm{R} \$ 0,17 / \mathrm{m}^{3}$. Dessa forma, parece que essa modalidade de concessão aponta para uma preocupação elevada com as perdas do sistema. Sendo a água cobrada na entrada do sistema, e só podendo faturar pelos volumes efetivamente consumidos, a concessionária terá interesse em reduzir as fugas do sistema, sob pena de comprometer seriamente suas receitas.

Não esquecendo que a titularidade do serviço de fornecimento de água é da municipalidade, os analistas políticos já anunciam ruidosos contenciosos entre o prefeito do município do Rio de Janeiro e o governador do Estado, acionista majoritário da CEDAE. Outrossim, há sérias dúvidas que esse processo chegue ao fim ainda nas atuais gestões governamentais.
Curiosa é a completa ausência no processo ao estímulo do gerenciamento da demanda através de quaisquer políticas, muito menos pela estrutura tarifária vaticinada, que não apresenta conceitos econômicos de estímulo ao uso eficiente do escasso recurso (custo marginal). Tal estrutura foi definida conforme Tabela 2, sendo o TRA e o TRE os valores apresentados acima.

\section{Os mecanismos complementares à política tarifária}

Além dos três modelos discutidos anteriormente, existem mecanismos complementares que podem aumentar a flexibilidade e a capacidade de intervenção do ente regulador, reduzindo o efeito da diferença de informações entre este e o prestador de serviço. São eles:

a. intervalos entre os processos revisionais;

b. licitações prévias à concessão para a definição da tarifa inicial a ser cobrada;

c. competição-padrão (yardstick competition).

Os intervalos entre os processo revisionais são necessários pelas incerteza e alterações das condições de oferta do serviço, exigindo uma redefinição das tarifas, podendo resultar em benefício ou em prejuízo para ambas as partes.

Quanto maior a aversão ao risco, diante das mudanças de mercado, maior o desejo do empreendedor em encurtar o intervalo de revisão. Isto poderia desestimular a eficiência da firma que, tendo os preços sempre reajustados, poderia esmorecer na perseguição de reduzir os gastos.

No caso do método de tarifação através do controle pela taxa interna de retorno, três aspectos importantes podem ser considerados na definição do intervalo de revisão: a) primeiro é recomendável que o período seja dilatado para evitar os custos diretos decorrentes ao processo de revisão; b) porém com o preço fixo por longo tempo, a empresa interessada em reduzir custos de forma a se apropriar dessa vantagem, repassaria para o consumidor o benefício do aperfeiçoamento do serviço, por meio de tarifas reduzidas, somente na próxima 
Tabela 2. Estrutura tarifária pré-estabelecida.

\begin{tabular}{|c|c|c|c|}
\hline \multirow[t]{2}{*}{ Categorias } & \multirow{2}{*}{$\begin{array}{c}\text { Classes de } \\
\text { consumo } \\
\text { (m3/Mês.Econ) }\end{array}$} & \multicolumn{2}{|c|}{ Tarifas } \\
\hline & & $\begin{array}{c}\text { Água } \\
\left(\mathrm{R} \$ / \mathrm{m}^{3}\right)\end{array}$ & $\begin{array}{c}\text { Esgotos } \\
\left(\mathrm{R} \$ / \mathrm{m}^{3}\right)\end{array}$ \\
\hline \multirow[t]{5}{*}{ Residencial } & o a 15 & $1,00 \times \operatorname{tra}$ & $1,00 \times$ tre \\
\hline & 16 a 30 & $2,20 \times \operatorname{tra}$ & $2,20 \times$ tre \\
\hline & 31 a 45 & $3,00 \times$ tra & $3,00 \times$ tre \\
\hline & 46 a 60 & $6,00 \times \operatorname{tra}$ & $6,00 \times$ tre \\
\hline & Acima de 60 & $8,00 \times \operatorname{tra}$ & $8,00 \times$ tre \\
\hline \multirow[t]{3}{*}{ Comercial } & o a 20 & $3,40 \times$ tra & $3,40 \times$ tre \\
\hline & 21 a 30 & $5,99 \times$ tra & $5,99 \times$ tre \\
\hline & Acima de 30 & $6,40 \times$ tra & $6,40 \times$ tre \\
\hline \multirow[t]{2}{*}{ Público } & o a 15 & $1,32 \times \operatorname{tra}$ & $1,32 \times$ tre \\
\hline & Acima de 15 & $2,92 \times$ tra & $2,92 \times$ tre \\
\hline \multirow[t]{4}{*}{ Indústria } & o a 20 & $4,70 \times \operatorname{tra}$ & $4,70 \times$ tre \\
\hline & 21 a 30 & $4,70 \times$ tra & $4,70 \times$ tre \\
\hline & 31 a 130 & $5,40 \times$ tra & $5,40 \times$ tre \\
\hline & Acima de 130 & $6,39 \times$ tra & $6,39 \times$ tre \\
\hline
\end{tabular}

revisão de tarifas; c) finalmente, a freqüência no controle da taxa de retorno, disposta a reduzir a margem de lucro do concessionário, poderá desestimular investimentos na fase final dos intervalos entre as revisões, com o receio de que uma queda na taxa de retorno, comprometa a capacidade de honrar os compromissos assumidos.

A aplicação do modelo custo marginal depende, também, da aversão ao risco por parte do concessionário. Quanto maior a aversão, tanto maior será o desejo da freqüência de revisões, de forma a passar para o usuário alterações no binômio custos e receitas. No caso de certa dose de confiança no desenrolar dos acontecimentos internos e externos com reflexo sobre a produção, o produtor poderá manifestar desejo de alongar o prazo, de forma a se apropriar do efeito da eficiência de seu processo produtivo.

No caso price-cap, a redução do intervalo pode reduzir a sua oportunidade de apropriar lucros extraordinários, enquanto que o alongamento do período, impediria que a queda nos custos do serviço fosse rapidamente repassada para os usuários, através de redução nas tarifas.

A licitação pelo preço é aquela que é definida no processo de licitação para exploração dos serviços, segundo o critério de menor preço ofertado. Essa tarifa inicial poderá ser regulada posteriormente, por um dos métodos acima discutidos. Uma das maiores críticas a esse processo é o embate que se estabelece entre o preço e a qualidade do serviço. A concessionária poderá descuidar dos aspectos de qualidade do serviço, de forma a reduzir seus custos, e assim ser capaz de oferecer o ser- viço com um menor custo. Há, ainda, os riscos de subinvestimentos, caso a firma sinta receio de não ter renovada a concessão.

No caso já comentado do município do Rio de Janeiro, o prazo de concessão é de 25 anos, remetendo os problemas das possíveis renovações para um futuro de longo prazo. Entretanto, na hipótese de nova licitação para concessão, surgem fortes vantagens a favor da concessionária vigente, devido principalmente às vantagens informacionais e ao acesso privilegiado a ativos intangíveis, tal como Pesquisa e Desenvolvimento (P\&D) e capital humano.

O yardstick competition é uma forma de regulação através de incentivos, também conhecida como regulação de desempenho, adotada no caso de monopólio natural. O regulador faz comparação de empresas que labutam no mesmo setor, de forma a estabelecer critérios de desempenho. Assim, a remuneração da firma pode ser determinada numa comparação, de forma que ela seja sensível aos custos e eficiências de suas congêneres. Esse método pode ser utilizado de forma complementar a qualquer critério de tarifação. A tendência tem sido a sua adoção juntamente com o método price-cap, no qual o preço-teto estabelecido é aquele necessário para remunerar adequadamente os investimentos de firmas congêneres de cada monopólio regional.

Embora a yardstick competition represente uma inovação regulatória importante, seu uso é mais adequado para o caso em que o mercado apresente uma quantidade de firmas que seja suficiente para evitar colusão na manipulação de dados entre elas. Vale registrar que esse método envolve elevados custos regulatórios no acompanhamento dos custos e do desempenho das empresas reguladas.

\section{A QUESTÃO OPERACIONAL DOS SUBSÍDIOS NAS TARIFAS}

Neste item, não se discute a validade da opção de se utilizar o subsídio nas tarifas de água. Economicamente, alguns autores defendem a idéia de que outras forma de distribuição de renda são mais eficientes, como um programa de renda mínima que preze pela manutenção dos demais preços público sem a figura do subsídio. Aqui, far-se-á, 
tão somente, uma exposição crítica do subsídio cruzado e orçamentário como política, julgada conveniente por alguns governos para garantir o acesso dos mais carentes ao serviço.

No setor de fornecimento de água, há os subsídios cruzados e os orçamentários. O subsídio cruzado é caracterizado por classes de usuário e faixas de consumo subsidiando os núcleos de menores rendas. Como já comentado, os usuários urbanos são divididos, em classe de usuários: i) residencial; ii) comercial; iii) industrial; e iv) público. Algumas companhias brasileiras admitem outras classes como o residencial social, que são pessoas de notória incapacidade de pagamento pelo serviço. Na cidade de São Paulo, há inclusive duas classes de usuários "sociais", uma delas sendo os favelados, numa clara disposição de tratar diferente os desiguais. De uma forma geral, a distinção de classes de usuário é feita de forma que o setor industrial e comercial, segundo o pressuposto que estes detendo maior capacidade de pagamento, subsidiem os demais consumidores, por meio de pagamento de tarifas acima da tarifa média.

Há querelas jurídicas sobre a legalidade ou ilegalidade dessa forma de subsídio cruzado, ainda sem uma jurisprudência definida. Porém, de fato, tal procedimento está presente nas empresas do setor de saneamento do Brasil (Alves, 1998).

A outra forma de subsídio cruzado seria o intraclasse. Por exemplo, usuários residenciais de alto poder aquisitivo pagam mais que o preço médio da água, segundo uma tarifa de bloco, de tal forma que cubra o baixo preço das tarifas para os de menor renda. Nesse ponto, é aceito como premissa que para rendas maiores, serão maiores os consumos de água.

Entretanto, há estudos sobre a capacidade distributiva das tarifas em bloco, que afirmam que a dificuldade política de estabelecer adequado patamar de consumo dos segmentos de menor renda, pode provocar o perverso efeito de classes carentes pagarem além do que deveriam, subsidiando classes mais abastadas.

Para clarear essa discussão, é feita uma diferenciação entre o modelo de subsídio que vigora no Brasil (orçamentário conjugado com cruzado), e o vaticinado pelo modelo chileno (puramente orçamentário). O modelo chileno foi escolhido por ter se notorizado como um dos mais severos programas de liberalização da economia mundial recente.

\section{O modelo brasileiro de subsídio para o fornecimento de água}

No Brasil, histórica e principalmente depois da instalação do PLANASA, as tarifas do setor de saneamento estiveram abaixo do preço real, numa soma de esforços para subsidiar o serviço, e como um instrumento de controle inflacionário. Convém esclarecer que esta política se estendeu para todos os preços determinados pelo poder público, como energia elétrica, preço dos combustíveis, preço das ligações telefônicas, entre outras.

O modelo de concessão para a iniciativa privada dos serviços de saneamento, especificamente o serviço de fornecimento de água e de recolhimento de esgotos, presente na agenda do governo brasileiro e de alguns Estados brasileiros, tem como norteador as recomendações do Projeto de Modernização do Setor de Saneamento (PMSS). O PMSS é o principal instrumento da Política Nacional de Saneamento, estando vinculado à Secretaria Especial de Desenvolvimento Urbano, ligado diretamente à presidência da república.

Esse programa preconiza o afastamento de qualquer perspectiva de sustentação de transferências negociadas de recursos do orçamento federal para a aplicação em programas e projetos de saneamento a cargo de Estados e municípios ou de entidades sob seu controle. Também afasta a possibilidade do orçamento federal prever verbas para subsidiar o consumo industrial ou o acesso da população de baixa renda aos serviços mantidos por empresas do ramo, fazendo decidida opção pelo subsídio cruzado.

Um dos textos produzidos pelo PMSS, intitulado "O Financiamento do Setor de Saneamento" esclarece e sugere que toda assistência federal deva ser exercida através de suas instituições financeiras, com base na avaliação de projetos submetidos pelos interessados. $\mathrm{O}$ tratamento favorecido a regiões mais pobres deve ser feito por intermédio da concessão de vantagens especiais - juros e prazos, por exemplo - para o financiamento dos projetos de investimento, devendo ser afastada qualquer hipótese de aplicações a fundo perdido.

\section{Modelo chileno de subsídios}

O modelo chileno de privatização ficou famoso em todo mundo, pela ampla liberalização da economia e privatização de grande partes dos seto- 
res, onde outrora o governo teve forte participação, principalmente na oferta da infra-estrutura nacional. O setor de saneamento não escapou dessa reformulação que teve início no final dos anos 80 . Apesar do sopro liberalizante da economia chilena, as operadoras dos serviços de saneamento continuam em boa parte em mãos do governo.

Os comentários que seguem estão baseados nas seguintes leis e decretos da república do Chile:

a. Lei No 18.778 de 17 de janeiro de 1989;

b. Lei No 19.338 de 20 de setembro de 1994;

c. Lei No 19.059 de 31 de maio de 1991;

d. Decreto No 529 de 20 de agosto de 1991 do Ministério da Fazenda da República do Chile (Ministerio de Hacienda);

e. Decreto No 453, de 12 de dezembro de 1989 do Ministério de Obras Públicas.

No governo chileno, preconiza-se que o subsídio será aplicável às tarifas fixas e variáveis para as residências em que o consumo mensal não supere $20 \mathrm{~m}^{3}$. A quantidade mensal de subsídio para a tarifa não poderá ser inferior (entre tarifas fixas e variáveis) a $25 \%$, nem superior a $85 \%$ e deverão ser os mesmos para os beneficiários de uma mesma região, que apresente um nível socioeconômico similar.

Para situar o leitor, convém ressaltar que o Chile adota uma tarifa fixa (definida em função do diâmetro que serve o usuário) e uma variável em função do volume efetivamente consumido. Detalhes adicionais são dados pela Tabela 3 .

A estrutura tarifária no Chile, baseada no custo marginal somado de uma tarifa fixa, é colocada de forma a cobrir integralmente os custos do serviço, inclusive com um valor adicional na forma de taxa, para a criação de um fundo para as futuras expansões do sistema. A figura do subsídio cruzado foi excluído da prática tarifária. Em seu lugar, para assegurar o serviço aos grupos de menor renda, o governo instituiu um subsídio orçamentário, onde a municipalidade custeia a diferença entre o preço real e o preço subsidiado, via uma transferência direta dos cofres do erário para os cofres da empresa prestadora do serviço.

Antes de seguir com maiores detalhes acerca das tarifas, é preciso ficar claro que, para famílias terem direito ao subsídio é preciso seguir um rito estabelecido pela municipalidade, que entre critérios econômicos, também exige adimplência com vários tributos, sob a pena de perder aquele.
Tabela 3. Tarifas de água em cidades chilenas, com valores de maio de 1999.

\begin{tabular}{|c|c|c|}
\hline & Tarifa $A^{a}$ & Tarifa $\mathrm{B}^{\mathrm{b}}$ \\
\hline $\begin{array}{l}\text { Tarifa variável entre o1/abril } \\
\text { e } 30 / \operatorname{nov}\left(\mathrm{R} \$ / \mathrm{m}^{3}\right)\end{array}$ & 1,34 & 0,76 \\
\hline $\begin{array}{l}\text { Tarifa variável entre o1/dez e } \\
\qquad 31 / \operatorname{mar}\left(\mathrm{R} \$ / \mathrm{m}^{3}\right)\end{array}$ & 1,06 & 0,71 \\
\hline $\begin{array}{l}\text { Sobreconsumo entre o1/dez e } \\
\qquad 31 / \operatorname{mar}\left(\mathrm{R} \$ / \mathrm{m}^{3}\right)\end{array}$ & 2,51 & 1,67 \\
\hline \multicolumn{3}{|l|}{ Tarifa fixa } \\
\hline Diâmetro (mm) & \multicolumn{2}{|c|}{ Tarifa (R\$/mês) } \\
\hline 13 & 2,63 & 1,92 \\
\hline 19 & 5,27 & 3,84 \\
\hline 25 & 10,54 & 7,67 \\
\hline 32 & 15,81 & 11,51 \\
\hline 38 & 23,71 & 17,26 \\
\hline 50 & 39,52 & 28,77 \\
\hline 75 & 92,20 & 67,12 \\
\hline 100 & 158,07 & 115,22 \\
\hline 125 & 242,37 & 176,44 \\
\hline 150 & 355,65 & 258,91 \\
\hline
\end{tabular}

a Na coluna Tarifa A estão as cidades de El Tabo, Isla Negra, Punta de Tralca y El Quisco; b Na coluna Tarifa B estão as cidades Cartagena e San Sebastian.

O sistema funciona de forma que o cidadão chileno beneficiado com o subsídio receba em sua casa a conta de água, onde deverá estar especificado o nível de subsídio presente naquela residência e o total a ser pago. Desse total, especifica-se que parcela será paga pelo cidadão e que parcela será subsidiada pelo governo, por meio da transferência direta desse valor do erário para a empresa responsável pelo serviço, num modelo acabado do chamado subsídio orçamentário.

Para a fixação das tarifas, há farta formulação matemática nas leis e decretos supracitados. A descrição pormenorizada dessas fórmulas não será apresentada neste texto, podendo ser encontrada nos sites já indicados. Entretanto, convém esclarecer alguns tópicos das tarifas.

As tarifas correspondentes à produção de água potável se estruturam da seguinte forma:

a. parcela variável por $\mathrm{m}^{3}$ em período fora-deponta de consumo: deve-se entender por ponta os meses do ano onde a demanda do sistema excede significativamente aos meses de menor consumo; 
b. parcela variável por $\mathrm{m}^{3}$ em período de ponta de consumo;

c. parcela por $\mathrm{m}^{3}$ de sobreconsumo no período de ponta.

As tarifas correspondentes ao serviço de distribuição de água se estruturam da seguinte forma:

a. parcela fixa mensal por cliente;

b. parcela variável por $\mathrm{m}^{3} \mathrm{em}$ período fora-deponta de consumo;

c. parcela variável por $\mathrm{m}^{3}$ em período de ponta de consumo;

d. parcela por $\mathrm{m}^{3}$ de sobreconsumo.

As tarifas correspondentes ao serviço final serão obtidas a partir da soma das tarifas consideradas em cada uma das etapas enumeradas acima. A taxa de custo de capital corresponderá à taxa interna de retorno oferecida pelo banco central do Chile, para seus instrumentos reajustáveis em moeda chilena de prazo igual ou maior de 8 anos, mais um prêmio de risco que não poderá ser inferior a $3 \%$ nem superior a $3,5 \%$.

Em todo caso, cada vez que as estimativas da taxa de custo do capital apresentem valores menores que a taxa mínima de $7 \%$ estabelecida pelo Ministério de Obras Pública, a taxa de custo de capital será igual à tal taxa mínima.

Para clarear a descrição do modelo chileno de tarifação apresenta-se um modelo de tarifas utilizado pela Companhia Águas Quintas, empresa responsável pela operação do serviço de água e esgoto de algumas cidades chilenas.

Buscando-se informações sobre as mudanças nos valores das tarifas entre os períodos pré e pós-implantação do novo modelo de tarifas, ficou claro que elas foram elevadas significativamente. Em algumas regiões, previa-se inclusive o aumento de mais de 400\% nas tarifas da época. De forma média, as tarifas sofreriam reajustes da ordem de 100\%, o que provocou forte reação da população. Diante desse quadro, o governo resolveu escalonar a recuperação das tarifas, com limite para o ano de 1998.

Ainda é cedo para definições conclusivas sobre o modelo indicado, e certamente a definição de tarifas é uma das principais dificuldades do setor. Outra dificuldade enfrentada é a poluição das águas, particularmente nas áreas urbanas mais importantes. Outro problema é o saneamento rural. A baixa capacidade de pagamento dos usuários inviabiliza o auto-financiamento das prestadoras de serviço por meio da política de tarifas adotada. A sociedade chilena ainda não encontrou solução para esse caso.

\section{CONCLUSÕES}

Da análise histórica brasileira apresentada, é possível verificar que não será somente por meio de simples reajustes de tarifas que será feita a recuperação da eficiência econômica das empresas de saneamento. Os problemas atuais enfrentados pelas prestadoras são tanto conjunturais como, principalmente, estruturais. O controle das tarifas como um dos instrumentos da pressão inflacionária, ingerências políticas dentro destas empresas, inadequado nível de eficiência administrativa e operativa, conformam o pano de fundo para explicar a situação pela qual atravessa o setor.

$\mathrm{Na}$ outra ponta, está a privatização, que aparece como uma proposta forte da agenda do atual governo brasileiro como forma de universalizar o atendimento dos serviços básicos de água e esgoto. A incapacidade de investimento do governo e a pretensa capacidade de investimento privado no setor são fortes argumentos utilizados por seus defensores. Outra vantagem argumentada seria a administração da empresa em bases gerenciais, afastando as interferências políticas externas.

A necessidade da criação de agências reguladoras para o serviço de saneamento oferecido por empresas privadas, considerando-se os contenciosos debates acerca das mesmas políticas tarifárias, marcará certamente esta nova fase do setor de saneamento no Brasil.

É preciso que no plano de governo para o setor esteja clara a opção que o Brasil deverá utilizar para subsidiar o oferecimento dos serviços indispensáveis de saneamento para as camadas de menores rendas. Estudos mais aprofundados da eficácia da redistribuição de renda por esse caminho deverão ser incentivados.

Em relação ao sistema que surge, o autor sugere flexibilização ampla do modelo, fortalecendo a participação municipal, a busca de novos parceiros, inclusive do setor privado, novas fontes de financiamento compatíveis com as atividades, novo arranjo institucional, concessão de subsídios explícitos às camadas menos favorecidas por parte dos três níveis de governo, e atuação com base empresarial. 
Os contornos decisivos do novo modelo de financiamento para o setor saneamento estão na dependência do desdobramento do processo de reforma tributária e fiscal. As esperanças que a reforma fiscal ficasse devidamente solucionada, são remotas. Até lá, soluções intermediárias, algumas delas apontadas anteriormente, podem ser implementadas. Entretanto, a construção do novo modelo, todavia, não dispensa a mobilização permanente do setor em torno de uma proposta de reforma do Estado e do sistema tributário brasileiro.

\section{REFERÊNCIAS}

ALVES, A. C. (1998). Saneamento básico: Concessões, Permissões e Convênios Públicos. Editora Edipro. São Paulo.

BRASIL (1995 a). Ministério do Planejamento e Orçamento. Secretaria de Política Urbana. Instituto de Pesquisas Econômica Aplicada. Diagnóstico do Setor Saneamento. Brasília. p. 251 (Série Modernização do Setor Saneamento, 7).

BRASIL (1995 b). Ministério do Planejamento e Orçamento. Secretaria de Política Urbana. Instituto de Pesquisas Econômica Aplicada. O Financiamento do Setor de Saneamento. Brasília. p. 142 (Série Modernização do Setor Saneamento, 2).

BRASIL $(1995$ c). Ministério do Planejamento e Orçamento. Secretaria de Política Urbana. Instituto de Pesquisas Econômica Aplicada. Regulação da Prestação de Serviços de Saneamento. Brasília. p. 278 (Série Modernização do Setor Saneamento, 6).

GALBRAITH, J. K. (1991). A era da incerteza. Livraria Pioneira Editora. São Paulo. $8^{\circ}$ Edição.

PARLATORE, A. C. (1999). Privatization of the Water Utility Sector in Brazil. In: Privatisation in Brazil: The Case of Public Utilities. International Seminar. BNDES. Rio de Janeiro.

RIO DE JANEIRO (1999). Secretaria Municipal de Obras e Serviços Públicos. Fundação Rio-Águas. Edital de Concorrência Pública para a concessão de serviço público para operação, manutenção e ampliação dos sistemas de abastecimento de água e esgotamento sanitário nas bacias hidrográficas da Baía de Sepetiba, Baixada de Jacarepaguá e das Praias oceânicas da zona sul. Texto disponível no site www.rio.rj.gov.br

\section{Tariff Practices in the Brazilian Sanitation Sector}

\begin{abstract}
This text presents a discussion on tariff practices in the sanitation sector, within the historical context of Brazilian policies for this sector. The main aspect studied is the period in which PLANASA (National Sanitation Plan) was involved, as well as the policies of the BNH (National Housing Bank), an agency which was later closed down. Thus, the situation of national economic problems is analyzed to correlate it to the current financial status of sanitation companies. The tariff practices in this sector are presented, together with their aims. For instance, Brazilian and Chilean practices are shown, observing the disparities in the existing policies regarding subsidies in both countries: in Brazil, with an indirect subsidy in the water and sewage accounts; in Chile, by means of direct forms. Finally, some indications for an initial diagnosis of obstacles of the financial structure in the Brazilian sanitation sector are obtained from the analysis.
\end{abstract}

Key-words: tariff; sanitation. 